\title{
Perspective taking during reading: An on-line investigation of the illusory transparency of intention
}

\author{
KRISTIN M. WEINGARTNER and CELIA M. KLIN \\ State University of New York, Binghamton, New York
}

\begin{abstract}
Although proficient readers must be reasonably successful at keeping track of what information they share with characters and what information is privileged to them, there is evidence that they are unable to do so with complete accuracy. Keysar (1994) used off-line tasks to demonstrate that readers sometimes mistakenly use privileged information when evaluating a character's interpretation of an ambiguous message. After we replicated Keysar's (1994) findings (Experiment 1), the results of an on-line task indicated that this "illusory transparency of intention" extends to natural reading (Experiment 2). In Experiment 3 , we provided preliminary support for the hypothesis that readers' accuracy in assessing a given character's perspective is influenced by whether or not that character is in the focus of the story. The results are discussed with regard to two competing theoretical views: the construal view and the standard view.
\end{abstract}

A common literary technique is to provide information to the reader that is not shared by the characters in the story. Thus, one of the skills readers need for successful comprehension is to keep track of what information they share with the characters and what information is privileged to them. Although proficient readers must be able to do this with reasonable success, it is not clear that they can do so with complete accuracy. This hypothesis is based in part on empirical findings from domains outside of reading that indicate that people are not always accurate at judging the perspective of others (for a review, see Nickerson, 1999). In particular, people often have difficulty appreciating the perspective of others who do not share their knowledge. For example, when giving directions, people sometimes fail to recognize that they are leaving out critical details about the area or about specific landmarks, overestimating the similarity between their own knowledge and the knowledge of those unfamiliar with the area (Kingsbury, 1968, as cited in Nickerson, 1999). This phe-

This research was supported by National Institute of Mental Health Grant R03 MH61839. Portions of this research were presented at the 42nd Annual Meeting of the Psychonomic Society (November 2001, Orlando, Florida). These experiments were conducted in partial fulfillment of the requirements for K.M.W.'s Master of Arts degree at SUNYBinghamton and conducted under the direction of C.M.K. We thank the members of K.M.W.'s thesis committee, Cynthia Connine and Albrecht Inhoff, for providing helpful recommendations regarding this project. We also thank William H. Levine and Alexandria E. Guzmán for comments on an earlier version of this manuscript, and Heather Christy, Michael Falcone, Jaclyn Levy, Mandi Marsh, and Shannon Sowle for their assistance in preparing experimental materials and with data collection. Correspondence concerning this article should be addressed to C. M. Klin, Department of Psychology, State University of New York, Binghamton, NY 13902-6000 (e-mail: cklin@binghamton.edu). nomenon is commonly referred to as the "curse of knowledge" (Camerer, Loewenstein, \& Weber, 1989; Hogarth, 1981; see also "false consensus effect," e.g., Ross, Greene, \& House, 1977 and "hindsight bias," e.g., Fischhoff, 1975) and has been shown to influence people's judgments about the knowledge and perspective of others in a variety of contexts from marketing and business interactions (Bazerman \& Neale, 1982; Camerer et al., 1989; Van Boven, Dunning, \& Loewenstein, 2000) to estimates of the popularity of a favored presidential candidate (Granberg \& Brent, 1983). In addition to being pervasive, this error in judgment has been found to be robust and difficult to eliminate, even when monetary rewards are offered for accurately assessing others' perspectives (Camerer et al., 1989) or when people are explicitly instructed to keep in mind the ambiguity of the situation (Griffin, Dunning, \& Ross, 1990).

One interesting instance of the curse of knowledge involves the perception of ambiguous stimuli. For example, in a study examining the interpretation of an ambiguous auditory stimulus (Newton, 1990, as cited in Nickerson, 1999), one group of participants (the tappers) was instructed to think of a familiar tune (e.g., "America the Beautiful") and tap it for a second group (the listeners). When asked to judge the likelihood that the listeners would successfully identify the tune, the tappers' estimates were significantly higher than the actual probability of correct identification. One explanation for this error is that the tappers based their estimates on a construal of the rhythm that was embellished, perhaps including vocals and instrumentals. Failing to realize that these embellishments were internally generated, the tappers did not appreciate the discrepancy between their own representation and that of the listeners. This led the tappers to underestimate the ambiguity of the stimulus 
and the difficulty of the listeners' task. More generally, the idea of construal (e.g., Barsalou, 1987; Bruner, 1957) is that there is a cognitive bias such that once people settle on an interpretation of an ambiguous stimulus, they fail to appreciate its ambiguity or the possibility of alternative interpretations (Griffin et al., 1990; Griffin \& Ross, 1991; Keysar, 1994).

Although not much attention has been paid to the assessments that readers make of story characters' perspectives, it is reasonable to hypothesize that assessing a character's perspective is not unlike assessing another person's perspective. Consistent with this, Keysar (1994) has provided initial evidence that readers sometimes act like the tappers, failing to accurately estimate a character's perception of an ambiguous stimulus. In Keysar's (1994) experiments, participants read scenarios similar to the sample passage in Table 1. Each passage involved two characters. In the critical message section of the passage, the writer (e.g., David) left a written message for an addressee (e.g., June). The message (e.g., "You wanted to know about the restaurant? Well, it was marvelous, just marvelous") was ambiguous in that it could be interpreted as either sarcastic or sincere. Earlier in the passage, information had been presented that served to disambiguate the message. Critically, this disambiguating information was accessible to the reader, but not to the addressee. Furthermore, the disambiguating information differed for the two versions of the passage. In the negative event version of the passage, the writer had a negative experience (e.g., David did not like the restaurant). Given this, readers were likely to arrive at a sarcastic interpretation of the critical message. In contrast, in the positive event version, David liked the restaurant, which

Table 1

Sample Passage From Experiment 1

\begin{abstract}
Introduction
David asked his office mate, June, to recommend a restaurant. His parents were in town and he wanted to take them to a good place. "I strongly recommend this new Italian place, called Tony's. I just had dinner there last night and it was marvelous. Let me know how you all enjoy it," said June who really liked Italian food. That evening, David and his parents ate there.
\end{abstract}

\section{Privileged information}

Negative event version. The food was unimpressive and the service was mediocre.

Positive event version. The food was indeed delicious and the service was impeccable.

\section{Critical message}

When David arrived at work the next morning, he did not find June at her desk. He remembered she was taking the morning off, so he left a note on her desk: "You wanted to know about the restaurant? Well, it was marvelous, just marvelous."

\section{Continuation}

Sarcasm-consistent. June writes back, "What didn't you like about the restaurant?"

Sincere-consistent. June writes back, "Would you like to eat there again this weekend? I can't wait to try the new vegetable lasagna." should have led readers to interpret the critical message as sincere.

The interesting question was whether readers would fall prey to the curse of knowledge, or whether they would keep track of the fact that the disambiguating information was not accessible to the addressee, and that it therefore could not influence the addressee's interpretation of the message. Just as the tappers "heard" an embellished version of the tune and failed to appreciate that the embellishments were not accessible to the listeners, in the negative event version readers may "hear" a sarcastic intonation in the critical message (i.e., ". . . marvelous, just marvelous") and fail to appreciate that this embellishment is not accessible to June. If so, readers may assume that June also heard sarcasm in the critical message in the negative event version, but not in the positive event version, and thus, that her interpretation of the critical message is in line with their own. In contrast, if readers do not fall prey to the curse of knowledge, they should disregard their privileged information when considering June's interpretation. Therefore, because the two versions of the passage are identical except for the privileged information, readers should assume that June's interpretation of the critical message does not differ across versions.

In Keysar's (1994) first experiment, when readers were asked for their interpretation of the critical message, not surprisingly they reported perceiving sarcasm more often when their privileged information suggested sarcasm (negative event version) than when no sarcasm was suggested (positive event version). More importantly, when asked for their estimates of June's interpretation of the message, readers more often indicated that she would perceive sarcasm in the negative event version than in the positive event version. Thus, readers' privileged knowledge had an influence not only on their own interpretation of the message, but on their assessments of June's, as well. This finding was replicated with a modified task when readers were asked to predict the addressee's response to the critical message (Gerrig, Ohaeri, \& Brennan, 2000; Keysar, 1994). Readers were asked to decide which of two possible continuations was more likely. One continuation was consistent with a sarcastic interpretation of the message, and the other was consistent with a sincere interpretation of the message. Referring to our sample passage (which is a modified version of a passage from Keysar, 1994), readers were asked to decide how June was more likely to respond if she were asked by another friend for a restaurant recommendation: Would she recommend a different restaurant (consistent with a sarcastic interpretation) or the same restaurant (consistent with a sincere interpretation)? Supporting the findings from Keysar's (1994) first experiment, readers were more likely to believe that June would recommend a different restaurant in the negative event version, where they perceived sarcasm, than in the positive event version. Keysar (1994) labeled this phenomenon the illusory transparency of in- 
tention: Despite June's lack of access to the disambiguating information, readers were under the illusion that David's intentions, sarcastic or sincere, were transparent to her.

Keysar's (1994) studies provided a valuable starting point for understanding perspective taking during reading. However, all of the measures were off-line, with readers making explicit judgments after reading the passages. Thus, the findings may not reflect processes that occur during natural reading. For example, in one experiment readers were asked explicitly if the addressee had interpreted the critical message as sarcastic. The possibility of sarcasm was highlighted further in another experiment, where the instructions elaborated on the concept of sarcasm and its uses. In Keysar's (1994) third experiment, although readers were no longer asked about the addressee's perception of sarcasm, they were asked explicitly to predict the addressee's future behavior. All of these measures invite slow and conscious responding and any number of strategic processes that are unlikely to occur during narrative comprehension under ordinary circumstances. For example, when asked to evaluate June's interpretation of the critical message, readers may have found it easiest to report their own interpretation. In addition, as noted by Gerrig, Ohaeri, and Brennan (2000), because no filler passages were used, there was a stark contrast between the positive and negative event versions. This may have caused readers' responses to be more polarized, contributing to the difference between the two versions. More generally, in all of these experiments the demand characteristics make it risky to generalize the findings to natural reading. Thus, one of the primary goals of the present set of experiments was to build on the original finding, asking about readers' accuracy in perspective taking during reading.

Experiment 1 was a replication of Keysar's (1994) offline study. We wanted to ensure that with the same method as Keysar's (1994), we could obtain the same pattern of results with modified stimuli and a different participant population. In Experiment 2, we attempted to generalize the effect from the off-line task to natural reading. Instead of asking participants to make explicit judgments, we measured reading times on a target line that was consistent with a sincere interpretation of the critical message. Finally, in Experiment 3 we investigated the influence of discourse focus on perspective taking.

\section{EXPERIMENT 1}

In Experiment 1, we replicated Keysar's (1994) third experiment with a revised set of materials. Each passage involved a writer (e.g., David) who left a message for an addressee (e.g., June) in the final line. A sample passage can be found in Table 1. A sarcastic interpretation of the writer's message (e.g., "You wanted to know about the restaurant? Well, it was marvelous, just marvelous") was suggested by the privileged information in the negative event version (e.g., David did not like Tony's), but not in the positive event version (e.g., David liked Tony's). Given Keysar's (1994) findings, we expected that readers' judgments about the addressee's interpretation of the message would be influenced by their privileged knowledge. If this is the case, readers should be more likely to select the sarcasm-consistent continuation (e.g., June writes back: "What didn't you like about the restaurant?") in the negative event version, when their privileged information suggests a sarcastic interpretation of the message, than in the positive event version, when it suggests a sincere interpretation of the message. On the other hand, if readers disregard their privileged information when judging the addressee's interpretation of the message, they should choose the sarcasm-consistent continuation at an equal rate for both the positive and negative event versions.

\section{Method}

Participants. Forty-eight undergraduates at the State University of New York at Binghamton participated as part of the requirement for an introductory psychology course.

Materials. There were a total of 18 experimental passages: 10 were modified versions of passages used by Keysar (1994), and 8 were new passages constructed in a similar format. A sample passage can be found in Table 1. The introduction of each passage described the interactions between two characters, a writer and an addressee. This was followed by the privileged information section, which included a description of a targeted event involving the writer. Information in this section was inaccessible to the addressee and differed for the two versions: In the negative event version, the writer had a negative experience, and in the positive event version, the writer had a positive experience. Across the two versions, information in this section was equated for length and used as many of the same words as possible. Each passage concluded with the critical message in which the writer left a written message for the addressee, commenting on the targeted event. This critical message was ambiguous and could be interpreted either as sarcastic or sincere. Finally, two possible continuations were provided at the end of each passage. Each continuation described how the addressee might react or respond to the writer's message. One alternative was consistent with a sarcastic interpretation of the critical message (sarcasmconsistent continuation), and the other was consistent with a sincere interpretation (sincere-consistent continuation).

Design. In order to keep the experimental session short, each participant read only 6 of the 18 passages. Three passages were presented in the negative event version, and 3 were presented in the positive event version. Across participants, the assignment of each passage to the two versions was counterbalanced, as was the presentation order of the two continuation alternatives.

Procedure. The participants were tested individually in an experimental session lasting approximately $15 \mathrm{~min}$. Each passage, along with the two possible continuations, appeared on a separate page in a booklet. There was no mention of sarcasm or irony in the instructions. The participants were informed only that a character in each of the stories would comment on some event or set of circumstances and that they were to decide how the other character was likely to respond. After reading each story, the participants circled the continuation that they believed to be more likely.

\section{Results and Discussion}

An alpha level of .05 was used across all experiments. As can be seen in Table 2, the results clearly replicate the findings from Keysar (1994): A larger percentage of 
Table 2

Experiment 1: Percentage of Sarcasm-Consistent Continuations

Sarcasm-Consistent

\begin{tabular}{cc}
\hline Version & $\begin{array}{c}\text { Sarcasm-Consistent } \\
\text { Continuations (in \%) }\end{array}$ \\
\hline Negative event & 23 \\
Positive event & 3 \\
Difference & $20 *$ \\
\hline$* p 05$. &
\end{tabular}

continuations consistent with the addressee's perception of sarcasm was chosen in the negative event version than in the positive event version, $23 \%$ and $3 \%$, respectively $[t(17)=4.64, S E M=.34]$. In other words, readers indicated that June's response to David's message "You wanted to know about the restaurant? Well, it was marvelous, just marvelous" was likely to be "What didn't you like about the restaurant?" more often when David did not like Tony's than when he did like Tony's. This occurred even though June did not have access to information about David's experience at Tony's. These findings demonstrate the illusory transparency of intention: Readers allowed their own interpretation of the message, based on privileged information, to influence their assessments of the uninformed addressee's interpretation.

It should be noted that although the effect size in the present experiment is similar to that in Keysar's (1994) Experiment 3, readers judged the addressee's interpretation to be sarcastic at a lower rate overall. In the negative event version, the percentage of sarcasm-consistent continuations chosen was $23 \%$ in the present experiment and $48 \%$ in that of Keysar (1994). For the positive event version, the percentages were $3 \%$ and $24 \%$ in the present experiment and that of Keysar (1994), respectively. The differences between experiments may be due, at least in part, to differences in the stimuli. For example, Gerrig, Ohaeri, and Brennan (2000) demonstrated that for some of the passages from Keysar's (1994) experiments, the critical messages (e.g., “. . . marvelous, just marvelous") were interpreted as sarcastic or sincere even in the absence of the privileged information. However, with the present set of passages, participants almost never found the critical message to be sarcastic in the positive event version. This suggests that, at least on average, the critical messages were not perceived as inherently sarcastic.

Regardless of the discrepancy in the base rate of responding between the two experiments, the difference between the negative event and the positive event versions is critical. That is, although the addressee's experience was identical in the positive and negative event versions, participants in both the present experiment and in Keysar (1994) indicated that the addressee perceived the message as sarcastic approximately $20 \%$ more often in the negative event version, where their privileged information suggested a sarcastic intention, than in the positive event version.

In summary, the present results, in combination with the results from Keysar (1994), provide evidence that readers do not always accurately estimate a character's perspective: Readers' privileged information influenced their assessments of a character's understanding of an ambiguous message. However, asking participants to read a story and then answer questions about it is likely to involve processes that are absent from natural reading. In addition, because each story in the experimental session described a character as having either a positive or negative experience, readers may have detected the polarity between the positive event and negative event versions. This may have led them to respond accordingly, matching sincere-consistent continuations with positive experiences, and sarcasm-consistent continuations with negative experiences (Gerrig, Ohaeri, \& Brennan, 2000). Both of these issues are addressed in Experiments 2A and 2B.

\section{EXPERIMENTS 2A AND 2B}

In Experiments 2A and 2B, we again examined readers' ability to take a character's perspective when it differed from their own. More specifically, we asked whether readers' privileged information influences their assessments of a character's perspective. However, in contrast to Experiment 1, where participants were asked to make explicit judgments after reading each passage, in the present experiment participants read normally. The dependent

Table 3

Sample Passage From Experiment 2

\section{Introduction}

David asked his office mate, June, to recommend a restaurant. His parents were in town and he wanted to take them to a good place. "I strongly recommend this new Italian place, called Tony's. I just had dinner there last night and it was marvelous. Let me know how you all enjoy it," said June, who really liked Italian food. That evening, David and his parents ate there.

\section{Privileged information}

Negative event version (Experiment 2A only). The food was unimpressive and the service was mediocre. When David arrived at work the next morning, he did not find June at her desk. He remembered she was taking the morning off, so he left a note on her desk:

Negative-sincere version (Experiment 2B only). The food was unimpressive and the service was mediocre. When David arrived at work the next morning, he did not find June at her desk. Not wanting to hurt her feelings, David left a note on her desk:

Positive event version. The food was indeed delicious and the service was impeccable. When David arrived at work the next morning, he did not find June at her desk. He remembered she was taking the morning off, so he left a note on her desk:

\section{Critical message}

"You wanted to know about the restaurant? Well, it was marvelous, just marvelous."

\section{Backgrounding and conclusion}

The next morning June planned a surprise party for David's birthday. He turned 40 in one week. She knew exactly

Target line. how to plan it, since David really liked Tony's.

Posttarget line. After June made the arrangements she e-mailed all of David's friends to fill them in on the plans.

\section{Comprehension question}

Did David and June work together? 
measure was reading time on a target line that was consistent with a sincere interpretation of the ambiguous message. For example, consider the target line from the sample passage in Table 3. June's conclusion that “. . . David really liked Tony's" is sensible only if she thought that David was being sincere when he wrote that the restaurant was "marvelous, just marvelous."

\section{Experiment 2A}

In Experiment 2A, passages appeared in either a positive event version or a negative event version, just as in Experiment 1. If the findings from Experiment 1 generalize to natural reading, readers' privileged knowledge should again influence their judgments about the addressee's interpretation of the critical message. Readers should therefore be more likely to think that June interprets David's message as sarcastic in the negative event version, where David does not like Tony's, than in the positive event version. If this is the case, the target line (e.g., June thinks that "David really liked Tony's") should be problematic in the negative event version, leading to a slowdown in reading. In contrast, the target line should seem perfectly sensible in the positive event version, where readers are likely to assume that June interpreted the critical message as sincere. Thus, reading times should be longer in the negative event version than in the positive event version.

In contrast, if the findings from Keysar (1994) and from Experiment 1 do not generalize to natural reading, readers should disregard their privileged knowledge when assessing June's interpretation of the critical message. If this is the case, their assessments should be the same in the negative and positive event versions, and the target line should be equally easy (or difficult) to integrate in the two versions. This would be indicated by similar reading times on the target line in the negative and positive event versions.

\section{Method}

Participants. Twenty-nine undergraduates at the State University of New York at Binghamton participated as part of the requirement for an introductory psychology course. The data from 1 participant who did not follow instructions were deleted. Therefore, the analyses were based on 28 participants.

Materials. A sample passage can be found in Table 3. Both the negative and positive event versions of the 18 passages from Experiment 1 were used, with a few modifications. First, following the critical message, an average of three lines of backgrounding material was added to take the writer out of focus and to reintroduce the addressee (e.g., June plans a surprise party for David's birthday). The backgrounding material did not refer to the events in the introduction or to the privileged information from the targeted event section. This was followed by a target line in which the addressee's beliefs about the writer's experience were indicated (e.g., June thinks that “. . . David really liked Tony's"). The addressee's beliefs were always consistent with a sincere interpretation of the critical message. Each passage concluded with a posttarget sentence that did not refer to the targeted event or to the critical message and that fit equally well with a sarcastic or a sincere interpretation of the critical message.

Twenty-two filler passages were included to obscure the manipulation. Each filler passage described the interactions between two or more characters, but these interactions were not obviously positive or negative, and sarcasm was never conveyed as a communicative intention. A yes/no comprehension question was generated for each experimental and filler passage to encourage the participants to read carefully and to obscure the manipulation. The number of correct "yes" and "no" responses was equated across the 40 passages. For the experimental passages, these questions did not address any information that was relevant to the targeted information.

Design. For each participant, experimental passages were randomly assigned with two constraints: (1) Each participant saw half of the passages in each version, and (2) each version of each passage was presented to half of the participants. The order of presentation was the same for all participants. Filler passages were interspersed among the experimental passages.

Procedure. The participants were tested individually in sessions that lasted approximately $45 \mathrm{~min}$. The passages were presented one line at a time on a computer monitor. The participants were instructed to read each passage for comprehension at their own pace. Each trial began with the presentation of the phrase READY FOR THE NEXT STORY in the center of the screen. The participants controlled the presentation of the text with a line advance key. Each keypress caused the present line to be erased and the next line to be presented. Immediately after the last line of the passage, pressing the line advance key caused the final line to be erased and the string of "???" to be presented for $750 \mathrm{msec}$. This cue was replaced with a yes/no comprehension question. The participants responded "yes" or "no" to the question by pressing corresponding keys on the response box. On trials in which the participants responded incorrectly, the word ERROR appeared in the center of the screen for $1 \mathrm{sec}$. If the participants responded incorrectly on three or more comprehension questions, the phrase PLEASE TRY TO BE MORE ACCURATE ON QUESTIONS was presented for $2 \mathrm{sec}$. The participants were given two breaks during the experiment. To familiarize the participants with the procedure, they completed three practice passages before starting the experiment.

\section{Results and Discussion}

The mean reading times for the target and posttarget lines for Experiment 2A are presented in Table 4. These values were calculated after discarding outliers as defined by Tukey's (1977) criterion; this eliminated $7.3 \%$ of the data. The pattern of results is consistent with the findings from Experiment 1: Participants took longer to read the target line in the negative event version $(2,136 \mathrm{msec})$ than in the positive event version $(2,014 \mathrm{msec})$. This $122-\mathrm{msec}$ difference was significant $\left[t_{1}(27)=2.56, S E M=47.7\right.$; $\left.t_{2}(17)=2.19, S E M=70.7\right]$. The slowdown in the negative event version was even larger on the posttarget line:

Table 4

Experiment 2: Mean Target Line and Posttarget Line Reading Times (in Milliseconds)

\begin{tabular}{lcc}
\hline & \multicolumn{2}{c}{ Reading Time } \\
\cline { 2 - 3 } \multicolumn{1}{c}{ Version } & Target Line & Posttarget Line \\
\hline Negative event & Experiment 2A & \\
Positive event & 2,136 & 1,826 \\
Difference & 2,014 & 1,686 \\
& $122^{*}$ & $140^{*}$ \\
Negative-sincere & Experiment 2B & \\
Positive event & 2,164 & 1,841 \\
Difference & 2,150 & 1,850 \\
\hline
\end{tabular}

$*_{p}<.05$. 
Reading times were $140 \mathrm{msec}$ longer in the negative event version than in the positive event version. This difference was also reliable $\left[t_{1}(27)=2.87, S E M=48.8\right.$; $\left.t_{2}(17)=2.59, S E M=53.7\right]$. It is interesting to note that reading times on the pretarget line (i.e., the line that preceded the target line) were similar for the negative and positive event versions $(p \mathrm{~s}>.7) .{ }^{1}$ This indicates that there was not a general slowdown in the negative event version, due, for example, to the complexity of processing sarcastic information. Instead, the large slowdown on the target and posttarget lines in the negative event version indicates that readers had difficulty integrating the sincere-consistent target line when the privileged information suggested a sarcastic interpretation of the writer's message. That is, readers appeared to have difficulty integrating June's belief that David "really liked Tony's," when they knew that he did not. One interpretation of this finding is that when readers' privileged information suggested a sarcastic interpretation of David's message that the restaurant was "marvelous, just marvelous," they assumed that June had the same perception. In other words, readers exhibited the illusory transparency of intention: They allowed their interpretation of the message, based on privileged information, to influence their judgments about the uninformed addressee's interpretation.

Although this experiment can be taken as evidence for the illusory transparency of intention, a second interpretation of the results is possible: Regardless of how readers assessed the addressee's interpretation of the critical message, they may have slowed down on the target line in the negative event version simply because there was a mismatch between June's beliefs and reality. In other words, even if readers disregarded their privileged knowledge and assessed June's interpretation of the critical message to be sincere in the negative event version, they may have had difficulty integrating the target line because June's belief that David liked Tony's is inaccurate. The goal of Experiment 2B was to distinguish between these two interpretations.

\section{Experiment 2B}

Experiment 2B was identical to Experiment 2A, except that the negative event version was replaced with a negative-sincere version (see the sample passage in Table 3). The negative-sincere version described the message writer having a negative experience (e.g., David did not like Tony's), just as in the negative event version from Experiments 1 and 2A, but information was added to the privileged information section to indicate that the critical message was written with a sincere intention. For example, before David leaves the message on June's desk, the passage states that he does not want to hurt June's feelings and so he conceals his true opinion about Tony's. David's comment that the restaurant was "marvelous, just marvelous" is therefore no longer sarcastic. Thus, even assuming that readers tend to mistakenly be- lieve that characters share their knowledge, there is no reason for them to believe that June will interpret the critical message as sarcastic. The target line should therefore follow naturally in both the negative-sincere and the positive event versions. Given this, the only cause for readers to slow down on the target line in the negative-sincere version is the mismatch between June's beliefs and reality (i.e., June believes that David liked Tony's, when he actually did not). Thus, if reading times are longer in the negative-sincere version than in the positive event version, we can conclude that the longer reading times in the negative event version in Experiment 2A were also due to the mismatch, rather than being evidence for the illusory transparency of intention. In contrast, if readers do not slow down on the target line in the negative-sincere version, this will suggest that the mismatch between June's beliefs and reality did not disrupt comprehension. This would allow us to conclude that the longer reading times in the negative event version in Experiment $2 \mathrm{~A}$ supported the existence of the illusory transparency of intention during natural reading.

\section{Method}

Participants. Twenty-eight undergraduates at the State University of New York at Binghamton participated as part of the requirement for an introductory psychology course. The data from 1 participant who did not follow instructions were deleted. Therefore, the analyses were based on 27 participants.

Materials. A sample passage can be found in Table 3. There were two versions of each passage: the positive event version from Experiment $2 \mathrm{~A}$ and a negative-sincere version. The negative-sincere version was similar to the negative event version from Experiment 2A, except that approximately one line of additional text (an average of six words) was included in the privileged information section that made a sarcastic interpretation of the critical message unlikely. Although the writer still had a negative experience (i.e., David did not like Tony's), the additional information suggested a sincere interpretation of the critical message (e.g., David did not want to hurt June's feelings). The same 22 filler passages from Experiment 2A were used.

Design and Procedure. The design and procedure were identical to those used in Experiment 2A.

\section{Results and Discussion}

Mean reading times for the target and posttarget lines are presented in Table 4 . These values were computed after discarding outliers (Tukey, 1977), which constituted $5.1 \%$ of the data. Reading times for the positive event and the negative-sincere versions were almost identical on both the target and posttarget lines $(p s>.7)$. This indicates that readers found June's belief that "David really liked Tony's" to be equally sensible in both versions. That is, readers experienced no comprehension difficulty on the target line in the negative-sincere version, even though June's beliefs were inconsistent with reality. Most importantly, this allows us to conclude that the slowdown in the negative event version in Experiment 2A was not due to the mismatch between June's beliefs and reality. Thus, we conclude that in the negative event version, after readers arrived at a sarcastic interpretation of the message based 
on their privileged information, they believed that the addressee would also infer sarcasm, despite the fact that the disambiguating information was privileged to them. The combined results from Experiments $2 \mathrm{~A}$ and $2 \mathrm{~B}$ provide evidence for the illusory transparency of intention during natural reading. More generally, the results demonstrate that readers are not always accurate at estimating a character's perspective.

\section{EXPERIMENT 3}

It is probably safe to assume that skilled readers are proficient at keeping track of which information they share with the characters in a story and which information they do not; otherwise, many narratives would be incomprehensible. Despite this, in Experiment 2 we established that there are at least some conditions under which readers fail to use privileged information appropriately. The next question is what those conditions are. An understanding of the influential text variables is necessary both to establish some boundary conditions for the illusory transparency of intention, as well as to work toward the broader goal of understanding the critical factors involved in perspective taking.

In Experiment 3, we examined the influence of discourse focus on perspective taking. Given the powerful role that focus has been shown to play in the comprehension of discourse more generally (e.g., Almor, 1999; Lea, Mason, Albrecht, Birch, \& Myers, 1998; McKoon, Ward, Ratcliff, \& Sproat, 1993; Myers, O'Brien, Albrecht, \& Mason, 1994), we hypothesized that it would also be influential in perspective taking. More specifically, we hypothesized that one reason why readers inaccurately assessed the addressee's perspective was that the addressee was not in focus when the critical message was presented. For example, the sample passage described David leaving the note rather than June reading the note. This may have served to focus readers' attention on the information that was accessible to David rather than the information that was accessible to June.

Although there has not been any prior research investigating the influence of focus on perspective taking, there is support for the hypothesis that the accessibility of information varies as a function of which character is in focus. For example, Lea et al. (1998) demonstrated that as a character moves in and out of focus during the course of a narrative, concepts associated with that character move in and out of the foreground in a similar manner. Given this, because David was foregrounded, or in explicit focus, when the critical message was presented, information known by him (e.g., his experience at the restaurant) should have been maintained in implicit focus (Garrod \& Sanford, 1990), being kept accessible. This may have made it difficult for readers to disregard that information, despite its privileged status, when considering June's interpretation of the critical message.

In the present experiment, we examined the hypothesis that focus plays an influential role during perspective
Table 5

Sample Passage From Experiment 3

\section{Introduction}

David asked his office mate, June, to recommend a restaurant. His parents were in town and he wanted to take them to a good place. "I strongly recommend this new Italian place, called Tony's. I just had dinner there last night and it was marvelous. Let me know how you all enjoy it," said June, who really liked Italian food. That evening, David and his parents ate there.

\section{Privileged information}

Negative event version. The food was unimpressive and the service was mediocre.

Positive event version. The food was indeed delicious and the service was impeccable.

\section{Focusing information}

Writer point of view (Experiment 3A). When David arrived at work the next morning, he thought about his schedule for the day. Before getting to work, he called to confirm his 11:00 meeting. Then he walked over to June's desk to leave her a reminder. At the end of the message he added:

Addressee point of view (Experiment 3B). When June arrived at work the next morning, she thought about her schedule for the day. Before getting to work, she called to confirm her 11:00 meeting. Then she spotted a message from David next to her coffee mug. She picked up the message and read it:

\section{Critical message}

"You wanted to know about the restaurant? Well, it was marvelous, just marvelous."

\section{Backgrounding and conclusion}

The next morning June planned a surprise party for David's birthday. He turned forty in one week. She knew exactly

Target line. how to plan it, since David really liked Tony's.

Posttarget line. After June made the arrangements she e-mailed all of David's friends to fill them in on the plans.

\section{Comprehension question}

Did David and June work together?

taking by manipulating which character - the writer or the addressee-was in focus when the critical message was presented. Consider the sample passage in Table 5. For both the positive and negative event versions, information was added before the critical message section that emphasized the writer's point of view (Experiment 3A) or the addressee's point of view (Experiment 3B). For example, in the writer point of view version, the passage describes David thinking about his schedule for the day and then leaving a note on June's desk, whereas in the addressee point of view version, the passage describes June thinking about her schedule and then reading a note from David.

The hypotheses are as follows. The results in Experiment $3 \mathrm{~A}$ should be the same as they were in Experiment 2A: Except for the addition of some text that serves to explicitly emphasize the writer's point of view, the passages are identical to those in Experiment 2A, where the writer's point of view was also emphasized. Thus, we expect to again find evidence for the illusory transparency of intention: Reading times on the target line should be longer in the negative event version than in the positive event version. In contrast, if focus influences perspective taking, there should be no (or weaker) evi- 
dence for the illusory transparency of intention in Experiment 3B, where June's point of view is emphasized. Readers should be less likely to activate the events from the privileged information section when assessing June's interpretation of the critical message, leading to similar reading times on the target line in the negative and positive event versions.

\section{Method}

Participants. Fifty-seven undergraduates at the State University of New York at Binghamton participated for course credit in Experiment 3A; 78 undergraduates participated in Experiment 3B. In both experiments, the data were deleted from 2 participants who made more than $25 \%$ comprehension question errors and from 5 participants who did not follow instructions. Therefore, the analyses were based on 50 participants in Experiment $3 \mathrm{~A}$ and on 71 participants in Experiment 3B.

Materials. A sample passage can be found in Table 5. The negative and positive event versions of the 18 experimental passages from Experiment $2 \mathrm{~A}$ were used, with one modification. In both versions, an average of 26 words were added between the privileged information section and the critical message section. The writer (Experiment $3 \mathrm{~A}$ ) or the addressee (Experiment $3 \mathrm{~B}$ ) was described as performing activities such as taking a lunch break, running errands, or completing tasks at work. The function of this additional text was to place the writer or addressee in the focus of the story. Across the versions, the focusing information was equated for length and used as many of the same words as possible. For example, in the writer point of view version of the sample passage, David arrived at work, thought about his schedule, confirmed a meeting, and then left a note on June's desk. In contrast, in the addressee point of view version of the sample passage, June arrived at work, thought about her schedule, confirmed a meeting, and then found a note from David. The same 22 filler passages from Experiment 2 were used.

Design and Procedure. The design and procedure were identical to those used in Experiment 2.

\section{Results and Discussion}

The mean reading times for the target and posttarget lines are presented in Table 6 . These values were calculated after discarding outliers (Tukey, 1977), which eliminated $5.8 \%$ of the data in Experiment $3 \mathrm{~A}$ and $5.7 \%$ of the data in Experiment 3B. In Experiment 3A, when the writer's point of view was emphasized, the results replicated those from Experiment 2A: Target line reading times were longer in the negative event version than in the positive event version. This $100-\mathrm{msec}$ difference was significant $\left[t_{1}(49)=3.56, S E M=28.1 ; t_{2}(17)=2.49\right.$, SEM $=$ 45.5]. The slowdown in the negative event version continued onto the posttarget line, although the 79-msec difference was not reliable $\left[t_{1}(49)=1.86, S E M=42.5, p=\right.$ $.069 ; t_{2}(17)=1.33$, SEM $\left.=54.4, p=.2\right]$.

Most important, in Experiment 3B, when the addressee's point of view was emphasized, there was a 96msec slowdown on the target line in the negative event version. This was significant in the subjects analysis $\left[t_{1}(70)=3.63, S E M=26.5\right]$ but did not reach significance in the items analysis $\left[t_{2}(17)=1.47, S E M=52.6, p=\right.$ .16. $]^{2}$ Although we hypothesized that emphasizing June's point of view would decrease the activation of information
Table 6

Experiment 3: Mean Target Line and Posttarget Line Reading Times (in Milliseconds)

Reading Time

\begin{tabular}{ccc} 
& \multicolumn{2}{c}{ Reading Time } \\
\cline { 2 - 3 } Version & Target Line & Posttarget Line \\
\hline \multirow{2}{*}{ Negative event } & 2,032 & 1,767 \\
Positive event & 1,932 & 1,688 \\
Difference & $100^{*}$ & 79 \\
\multicolumn{1}{c}{ Experiment 3B: Addressee Point of View } \\
Negative event & 2,009 & 1,724 \\
Positive event & 1,913 & 1,718 \\
Difference & $96^{*}$ & 6 \\
\hline * & &
\end{tabular}

$* p<.05$.

not accessible to her, readers' privileged information continued to influence their assessments of her interpretation of the critical message.

One explanation for this finding is that the illusory transparency of intention is a powerful phenomenon. More specifically, once readers interpreted the critical message as sarcastic in the negative event version, they were unable to appreciate its inherent ambiguity or to reinterpret it from the character's point of view, regardless of which character was in focus. Given this, the manipulation we used may have been too subtle to eliminate the illusory transparency of intention. Consistent with this hypothesis, several studies have found that readers will take a character's perspective only when they have been encouraged to pay attention to perspective, either directly, by instructing them do to so (e.g., Albrecht, O'Brien, Mason, \& Myers, 1995; O’Brien \& Albrecht, 1992), or indirectly, by having them perform a task such as memorizing a floor plan before reading (e.g., Morrow, Bower, \& Greenspan, 1989; Morrow, Greenspan, \& Bower, 1987). In the absence of these types of instructions, readers have been shown to be less likely to take a character's perspective (Albrecht et al., 1995; O'Brien \& Albrecht, 1992).

However, despite finding no influence of focus on the target line, the pattern of reading times on the posttarget line tells a different story. In contrast to the results of Experiments $2 \mathrm{~A}$ and $3 \mathrm{~A}$, where the slowdown in the negative event version continued onto the posttarget line, in Experiment $3 \mathrm{~B}$ reading times on the posttarget line did not differ across versions $(p s>.6)$. Given this, focus seems to have had a late influence on perspective taking.

We offer the following interpretation of our results: Regardless of which character was in focus, readers initially assumed that June's interpretation of the message was consistent with their own: "Marvelous, just marvelous" was perceived as sarcastic in the negative event version and sincere in the positive event version. This led to a slowdown on the target line in the negative event version for Experiments $3 \mathrm{~A}$ and $3 \mathrm{~B}$, just as it did in Experiment 2A. However, in contrast to the results of Experiments $2 \mathrm{~A}$ and $3 \mathrm{~A}$, where the size of the slowdown on the posttarget line in 
the negative event version was comparable to that on the target line, there was absolutely no slowdown on the posttarget line in Experiment 3B, when the addressee's point of view was emphasized. It appears that when June was in focus, readers were able to quickly restore coherence by reassessing her interpretation of the critical message. More specifically, they quickly realized that she did not have access to the privileged information. This result is particularly impressive given that prior studies have shown that readers often do not take a character's perspective unless explicitly instructed to do so (Albrecht et al., 1995; O'Brien \& Albrecht, 1992). In contrast to explicit instructions, the present manipulation was quite subtle. Given this, a stronger manipulation of focus might provide an even cleaner set of results.

\section{GENERAL DISCUSSION}

To build suspense and intrigue, narratives often provide information to the reader that is not shared by the characters, or that is shared by some of the characters and not others. Clearly, skilled readers must be reasonably proficient at keeping track of who knows what, or many narratives would be incomprehensible. However, Keysar (1994) demonstrated that in at least some circumstances, readers fail to accurately estimate a character's perspective, acting as if the character has access to information that is actually privileged to the readers. In the present set of experiments, we first asked whether these findings were dependent on the off-line measures that have been used (Gerrig, Ohaeri, \& Brennan, 2000; Keysar, 1994), with readers making explicit judgments about a character's interpretation of an ambiguous message, or whether they generalize to natural reading. Second, in order to better understand the nature of the phenomenon, we asked what factors influence readers' accuracy in estimating a character's perspective.

After we replicated the basic finding (Gerrig, Ohaeri, \& Brennan, 2000; Keysar, 1994) with an off-line measure in Experiment 1, in Experiments 2A and 2B a reading time measure was used to determine whether the phenomenon generalized to natural reading. For each passage, a target line was added in which the addressee made a comment that was consistent with a sincere interpretation of the critical message and inconsistent with a sarcastic interpretation. The findings in Experiment 2A paralleled those from the off-line task in Experiment 1: Reading times on the target and posttarget lines were longer in the negative event version, where readers' privileged information supported a sarcastic interpretation of the critical message, than in the positive event version. After ruling out an alternative interpretation in Experiment 2B, we concluded that readers had more difficulty integrating the sincere-consistent target line in the negative event version because they believed that the addressee had interpreted the critical message as sarcastic. This occurred even though the addressee lacked access to the information that led readers to a sarcastic interpretation.
In addition to providing evidence that the illusory transparency of intention occurs during natural reading, the pattern of findings from Experiment $2 \mathrm{~B}$ demonstrates that they are not due to a simple memory failure. As Keysar (1998) noted with a similar "concealment" condition, readers did not simply confuse what they knew with what the addressees knew. If the findings had been due to this type of confusion, there should have been a slowdown in the negative-sincere version of Experiment 2B, where readers knew that David disliked the restaurant but June commented that he liked the restaurant.

Finally, the results of Experiment 3 provide a first step toward understanding the types of factors that influence the accuracy with which readers estimate a character's perspective. Given previous demonstrations that when characters are in explicit focus, information relevant to them is maintained in implicit focus and is kept easily accessible (e.g., Garrod \& Sanford, 1990; Lea et al., 1998), we hypothesized that focus should also influence perspective taking. More specifically, we hypothesized that when a character was in focus, readers would be more likely to keep track of what information was available to them. The results of Experiment 3 provided some preliminary support for this hypothesis. When the addressee (e.g., June) was in focus, readers quickly realized that she did not have access to the privileged information.

How can the overall pattern of results be explained? One possibility is that the findings are the product of a general cognitive bias (Keysar, 1994). According to the idea of construal, once people settle on an interpretation of an ambiguous stimulus, they fail to appreciate its ambiguity and thus the possibility of alternative interpretations (e.g., Griffin et al., 1990; Griffin \& Ross, 1991; Keysar \& Bly, 1995). Given this, after readers arrived at a sarcastic interpretation of David's message in the negative event version, the phrase "marvelous, just marvelous" sounded unambiguously sarcastic to them; in the positive event version, the same phrase sounded unambiguously sincere. Thus, readers could not imagine it being interpreted differently by the addressee. Similarly, given this view, in the negative-sincere version in Experiment 2B, once readers knew that David was trying to be careful not to hurt June's feelings, the phrase "marvelous, just marvelous" no longer sounded sarcastic, but was perceived as kind, or sincere, leading them to assume that June would also find the message to be sincere. More generally, readers assumed that the addressee would find the writer's intentions, whatever they were, to be transparent, despite the fact that the addressee lacked access to the information that served to disambiguate the critical message.

An alternative explanation raised by both Keysar (1994, 2000) and Gerrig, Ohaeri, and Brennan (2000; see also Gerrig, Brennan, \& Ohaeri, 2000) is that the findings were the result of readers' expectations about rational behavior in communication. According to most theories of language use, conversation is governed by a cooperative principle (Grice, 1975), with speakers attempting to create messages such that their intended meaning will be 
understood. Given this "standard view" (Keysar, 2000), readers assumed that David was a cooperative communicator who attempted to create a message that was comprehensible to June. Therefore, when David disliked the restaurant he would not have told June that the restaurant was "marvelous, just marvelous" unless he believed that she could understand that he was being sarcastic. Furthermore, the argument goes, if David believed that June could understand his message, she probably did. Thus, according to the standard view, readers thought that June interpreted David's message as sarcastic in the negative event version, not because they themselves knew that his message was sarcastic, but because they believed that David, as a cooperative communicator, managed to successfully convey to June that he did not like the restaurant.

Where does this leave us? Although our findings do not definitively differentiate between the construal view and the standard view, the results of the focus manipulation in Experiment 3 are suggestive. Consider the following logic: If, as the standard view predicts, readers assume that David is a cooperative communicator who will make his message understandable to June, this should be true regardless of which character is in focus. In other words, in the negative event version of Experiments $3 \mathrm{~A}$ and $3 \mathrm{~B}$ readers should have assumed that David would not have written that the restaurant was "marvelous, just marvelous" unless June was able to understand that he was being sarcastic. Changing the focus from David's point of view to June's should not have made this any less likely. In contrast, given the construal explanation, readers should be less likely to "hear" the critical message in David's sarcastic voice if the critical message is presented from June's perspective. Thus, to the extent that a change in focus decreased readers' use of privileged information, this demands a modification of the standard view, perhaps suggesting that when characters are not in focus, readers will attend less to their role as cooperative communicators. Future research is necessary to better understand the influence of focus on perspective assessments and to provide a more decisive contrast of the two views.

In summary, the present set of results builds on Keysar's (1994) findings, demonstrating that there are conditions under which readers fail to accurately keep track of what information is privileged to them. Readers sometimes fall prey to the curse of knowledge, overestimating the similarity between their own knowledge and that of others, just like the tappers (Newton, 1990, as cited in Nickerson, 1999) or the person giving directions to a lost motorist. In this way, not only do the present findings contribute directly to a theory of text comprehension, but they are consistent with the idea that many of the cognitive processes involved in reading are not unique to reading. Thus, our understanding of readers' beliefs about fictional characters such as David and June should benefit greatly from an understanding of people's beliefs about each other.

\section{REFERENCES}

Albrecht, J. E., O’Brien, E. J., Mason, R. A., \& Myers, J. L. (1995). The role of perspective in the accessibility of goals during reading. Journal of Experimental Psychology: Learning, Memory, \& Cognition, 21, 364-372.

ALMOR, A. (1999). Noun-phrase anaphora and focus: The informational load hypothesis. Psychological Review, 106, 748-765.

BARSALOU, L. W. (1987). The instability of graded structure: Implications for the nature of concepts. In U. Neisser (Ed.), Concepts and conceptual development: Ecological and intellectual factors in categorization. Emory symposia in cognition, 1 (pp. 101-140). New York: Cambridge University Press.

Bazerman, M. H., \& Neale, M. A. (1982). Improving negotiation effectiveness under final offer arbitration: The role of selection and training. Journal of Applied Psychology, 67, 543-548.

BRUNER, J. S. (1957). Going beyond the information given. In H. Gruber, K. R. Hammond, \& R. Jesser (Eds.), Contemporary approaches to cognition (pp. 41-69). Cambridge, MA: Harvard University Press.

Camerer, C. F., Loewenstein, G., \& Weber, M. (1989). The curse of knowledge in economic settings: An experimental analysis. Journal of Political Economy, 97, 1232-1254.

FiscHHOFF, B. (1975). Hindsight $\neq$ foresight: The effect of outcome knowledge on judgment under uncertainty. Journal of Experimental Psychology: Human Perception \& Performance, 1, 288-299.

GARROD, S., \& SANFORD, A. J. (1990). Referential processes in reading: Focusing on roles and individuals. In D. A. Balota, G. B. Flores d'Arcais, \& K. Rayner (Eds.), Comprehension processes in reading (pp. 465-485). Hillsdale, NJ: Erlbaum.

GerRig, R. J., BrenNAN, S. E., \& OHAERI, J. O. (2000). What can we conclude from speakers behaving badly? Discourse Processes, 29, 173-178.

Gerrig, R. J., Ohaeri, J. O., \& Brennan, S. E. (2000). Illusory transparency revisited. Discourse Processes, 29, 137-159.

Granberg, D., \& Brent, E. (1983). When prophecy bends: The preference-expectation link in U.S. presidential elections, 1952-1980. Journal of Personality \& Social Psychology, 45, 477-491.

GRICE, H. (1975). Logic and conversation. In P. Cole \& J. L. Morgan (Eds.), Syntax and semantics: Vol. 3 (pp. 41-58). New York: Academic Press.

Griffin, D. W., Dunning, D., \& Ross, L. (1990). The role of construal processes in overconfident predictions about the self and others. Journal of Personality \& Social Psychology, 59, 1128-1139.

GRIFFIN, D. W., \& Ross, L. (1991). Subjective construal, social inference, and human misunderstandings. In M. Zanna (Ed.), Advances in experimental social psychology: Vol. 24 (pp. 319-359). New York: Academic Press.

Hogarth, R. M. (1981). Beyond discrete biases: Functional and dysfunctional aspects of judgmental heuristics. Psychological Bulletin, 90, 197-217.

KEYSAR, B. (1994). The illusory transparency of intention: Linguistic perspective taking in text. Cognitive Psychology, 26, 165-208.

Keysar, B. (1998). Language users as problem solvers: Just what ambiguity problem do they solve? In S. R. Fussell \& R. J. Kreuz (Eds.), Social and cognitive psychological approaches to interpersonal communication (pp. 175-200). Mahwah, NJ: Erlbaum.

Keysar, B. (2000). The illusory transparency of intention: Does June understand what Mark means because he means it? Discourse Processes, 29, 161-172.

KeYSAR, B., \& BLY, B. (1995). Intuitions of the transparency of idioms: Can one keep a secret by spilling the beans? Journal of Memory \& Language, 34, 89-109.

LeA, R. B., MAson, R. A., Albrecht, J. E., Birch, S. L., \& Myers, J. L. (1998). Who knows what about whom: What role does common ground play in accessing distant information? Journal of Memory \& Language, 39, 70-84.

McKoon, G., Ward, G., Ratcliff, R., \& Sproat, R. (1993). Syntactic prominence effects on discourse processes. Journal of Memory \& Language, 32, 56-75.

Morrow, D. G., Bower, G. H., \& Greenspan, S. E. (1989). Updating 
situation models during narrative comprehension. Journal of Memory \& Language, 28, 292-312.

Morrow, D. G., Greenspan, S. E., \& Bower, G. H. (1987). Accessibility and situation models in narrative comprehension. Journal of Memory \& Language, 26, 165-187.

MYers, J. L., O'Brien, E. J., Albrecht, J. E., \& Mason, R. A. (1994). Maintaining global coherence during reading. Journal of Experimental Psychology: Learning, Memory, \& Cognition, 20, 876-886.

NiCKERSON, R. S. (1999). How we know-and sometimes misjudgewhat others know: Imputing one's own knowledge to others. Psychological Bulletin, 125, 737-759.

O'BRIEN, E. J., \& ALBRECHT, J. E. (1992). Comprehension strategies in the development of a mental model. Journal of Experimental Psychology: Learning, Memory, \& Cognition, 18, 777-784.

Ross, L., Greene, D., \& House, P. (1977). The false consensus effect: An egocentric bias in social perception and attribution processes. Journal of Experimental Social Psychology, 13, 279-301.
TukeY, J. W. (1977). Exploratory data analysis. Reading, MA: AddisonWesley.

Van Boven, L., Dunning, D., \& Loewenstein, G. (2000). Egocentric empathy gaps between owners and buyers: Misperceptions of the endowment effect. Journal of Personality \& Social Psychology, 79, 66-76.

\section{NOTES}

1. Whereas the target and posttarget lines were similar in length across items, there was a significant amount of variability in the length of the pretarget line across items. Given this, the analyses for the pretarget line were based on reading times per character.

2. In Experiments $3 \mathrm{~A}$ and $3 \mathrm{~B}$, reading times on the pretarget line were similar for the negative and positive event versions $(p s>.7)$. Again, this makes evidence for a slowdown on the target line (Experiments $3 \mathrm{~A}$ and $3 \mathrm{~B}$ ) and posttarget line (Experiment $3 \mathrm{~A}$ ) in the negative event version all the more impressive.

(Manuscript received May 1, 2002;

revision accepted for publication April 26, 2004.) 